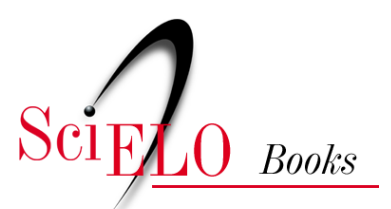

\title{
Histórias do Dr. Luiz Fernando Rocha Ferreira da Silva (dezembro de 1999)
}

\author{
Virgínia Schall
}

\section{SciELO Books / SciELO Livros / SciELO Libros}

SCHALL, V. Histórias do Dr. Luiz Fernando Rocha Ferreira da Silva (dezembro de 1999). In: Contos de Fatos: histórias de Manguinhos [online]. Rio de Janeiro: Editora FIOCRUZ, 2001, pp. 241-253. ISBN: 978-85-7541-614-3. Available from: doi: 10.7476/9788575416143.0018. Also available in ePUB from: http://books.scielo.org/id/hdq6f/epub/schall-9788575416143.epub.

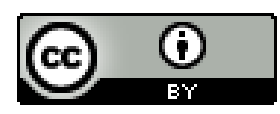

All the contents of this work, except where otherwise noted, is licensed under a Creative Commons Attribution $\underline{4.0 \text { International license. }}$

Todo o conteúdo deste trabalho, exceto quando houver ressalva, é publicado sob a licença Creative Commons Atribição 4.0. 


\section{Histórias do Dr. \\ Luiz Fernando Rocba \\ Ferreira da Silva}

(dezembro de 1999)

Manguinhosé razão, lógica, método cientifico.

Mas étambém sonho e poesia. Desde o início.

Luiz Fernando Ferreira, Poetas de Manguinhos.

Tuiz Fernando sempre me pareceu um cientista excêntrico, uma 1 personalidade marcante, desde o seu modo particular de andar, os ombros em balanço oblíquo, parecendo meio suspenso, quase em vôo (pois deve espelhar o espírito - viajante permanente). Suas expressões e histórias, por vezes enigmáticas, e sobretudo o seu modo de falar - desde a cadência, genuinamente carioca, até a forma de se expressar, entremeando sempre o raciocínio com metáforas e imagens - nos conduzem por atmosferas de sonho e imaginação. Quando narra um episódio, é possível viajar com ele e quase sentir cheiros e sabores. Foi assim que o escutei certa vez, contando sobre o itinerário, hábito de longos anos, que costuma fazer quando sai de Manguinhos ao entardecer para ir ao centro da cidade. Ali, segue pela Rio Branco, cortando ruas transversais e paralelas, no rastro dos sebos, em busca de raridades literárias e científicas, e termina o roteiro com um café acompanhado de chocolate recheado de menta na Kopenhagen. Como diz, o encontro do calor do café com o chocolate faz recender o sabor da mistura - aromatizado de menta - a descer derretendo, submergindo corpo e alma em prazer e doçura. 
Já se tornaram lenda em Manguinhos as suas histórias sobre Ricamor, o espectro noturno da mais bela mulher moura, morena de olhos pretos, que surge de repente, apenas para alguns eleitos, nos mais inusitados e misteriosos lugares do campus da Fiocruz, fulgurante sobre um cavalo, uma imagem enevoada e sublime que deixa encantado e inerte quem a vê. Ainda tem o mistério do símbolo enterrado sob o Castelo de Manguinhos, a cinco metros de profundidade, uma pedra e uma espada, bem no centro da base, um quadrante de posição estratégica, que seria o túmulo simbólico do último grão-mestre templário, Jacques de Molay, queimado vivo em 1314. Teria Oswaldo Cruz construído a fortaleza em um lugar sagrado, voltado para Jerusalém, como as catedrais góticas da Europa? E como surgiu a idéia do suposto vínculo milenar com a Ordem do Rei Artur? Luiz Fernando nos deixa, assim, mergulhados em fantasia, desafiando a razão que emana do templo da ciência.

Quem escuta o seu depoimento sobre o Programa deVocação Científica (Provoc) no vídeo que apresenta a Escola Politécnica da Saúde Joaquim Venâncio, percebe quanto do sonho o Dr. Luiz Fernando tem feito se transformar em realidade. Concebeu e auxiliou na implantação do programa que hoje já está se tornando uma rede nacional, ir radiando-se de Manguinhos para todo o país, iniciando jovens do ensino médio em ciência. Como afirma, "a oportunidade que eu tive de cedo vivenciar o ambiente de Manguinhos, que freqüentei desde menino por razões familiares, eu queria estender a outros. Por isso criei o Provoc, para botar aqui jovens que pudessem aprender bem cedo o que é ciência. Eu acredito que o sistema mais competente de formar pesquisadores se dá na relação mestre-aprendiz, pois passa por questões não só racionais, mas emocionais, o discípulo repete o mestre, gosta do mestre, o mestre do discípulo. (...) Estou convencido de que o verdadeiro processo pedagógico, em que pese a importância muito grande dos cursos de mestrado e doutorado, não se dá na hora da tese, é dentro do laboratório que o aluno vai aprender. Quanto mais cedo começar e quanto mais tempo durar, melhor". 
Minha intenção de ouvir as histórias do Luiz Fernando era antiga. Assim, no fim do ano passado, encontramo-nos na entrada do prédio da Ensp e combinamos a entrevista. Ao chegar em sua sala, encontrei-o conversando com a museóloga Margareth Aragão, que pôde compartilhar comigo da narrativa saborosa de quem fala como que por meio de crônicas. Aqui, passo a relatar o que foi possível registrar, o que é pouco perto de tudo o que ouvi e a velocidade da minha escrita não conseguiu acompanhar.

\section{Origens e História: da esquistossomose à paleoparasitologia}

Para Luiz Fernando, que criou e desenvolveu uma nova área de estudo, a paleoparasittologia, esta foi a sua mais importante invenção. Na introdução ao seu livro escrito em colaboração com mais outros dois pesquisadores, ${ }^{65}$ percebe-se que a paleoparasitologia parece um desiderato em sua vida. Embora diga que começou por uma motivação indireta, ele afirma que há outras motivações de alma que fazem o pano de fundo: "Sempre gostei de histórias do passado, e na paleoparasitologia eu consegui misturar isso". Como relata, desde menino foi fascinado pela história, ia em busca das origens das coisas e ansiava por entender a sua evolução. $\mathrm{Na}$ biblioteca do pai, médico, saciava a sede em livros de história da medicina, e destaca entre seus heróis dos tempos de estudante Darwin e Haeckel, cujos livros - A Origem das Espécies, Enigmas do Universo e Origem do Homem - eram suas referências. $E$ foi para compreender a ordem do universo que elegeu como campo de estudo a parasitologia, próxima da zoologia, chegando à paleoparasitologia em busca de pistas sobre a autoctonia da esquistossomose.

\footnotetext{
65. FERREIRA, L. F.; ARAÚJO, A \& CONFALONIERI, U. Paleoparasitologia no Brasil. Rio de Janeiro: PEC/Ensp, 1988.
} 
Sua pesquisa sobre a epidemiologia da esquistossomose o levou a ler um artigo do Prof. Caio Benjamim Dias em colaboração com o Prof. Magalhães publicado nas Memórias do Instituto Oswaldo Cruz. ${ }^{66} \mathrm{No}$ artigo, eles defendiam a autoctonia da esquistossomose na América, o que, naépoca, era uma heresia, uma suposição contrária a tudo o que ele ouvira dos professores da faculdade até então. Segundo Luiz Fernando, "como gosto das heresias, me interessei". Começou por fazer uma cuidadosa revisão bibliográfica, e deparou-se com um artigo de Sir Armand Ruffer que demonstrava o encontro de ovos de Schistosomahaematobium em múmias egípcias por ele examinadas. Esse parasito, encontrado na África, é responsável pela forma urinária da esquistossomose autóctone no continente africano. Na mesma ocasião, deparou-se com o livro Parasitismoe Migrações Pré-bistóricas, de Olímpio da Fonseca, que procurava desvendar rotas de migração de populações primitivas da África para a América. Partindo da evidência de certos parasitos encontrados em populações isoladas dos dois continentes, o autor queria demonstrar, com evidências indiretas, a presença de sintomas da esquistossomose em índios, como, por exemplo, um quadro de hipertensão porta detectado nos aborígines. Entretanto, a questão permanecia no terreno das suposições, e o Dr. Luiz Fernando queria uma resposta clara.

A leitura de trabalhos clássicos e sobre técnicas de arqueologia e antropologia indicou um caminho possível: investigar a presença de ovos de Schistosoma mansoni em fezes pré-colombianas da América. Enveredou por essa linha e encontrou dois companheiros, os jovens pesquisadores Adauto Araújo (veja história adiante) e Ulisses Confalonieri, dispostos a debruçar de corpo e alma, junto com o mestre, sobre o que ele considerava uma heresia. Muitos trabalhos foram realizados em colaboração com arqueólogos brasileiros. Como conta Luiz Fernando, diferentemente dos arqueólogos

\footnotetext{
${ }^{66}$ MAGALHÃES, B. F. \& DIAS, C. B. Esquistossomose de Manson: estudos, Memórias do Instituto Oswaldo Cruz, 41: 363-446, 1944.
} 
estrangeiros que vemos nos documentários e filmes americanos e ingleses e nos livros de Agatha Christie, os profissionais brasileiros não contam com facilidades: eles escavam, peneiram, transportam, etiquetam, catalogam, analisam, ou seja, processam todas as etapas com as próprias mãos. E foram numerosas as colaborações com arqueólogos de diversas instituições brasileiras e sul-americanas. Ao longo de 21 anos de trabalho e de uma procura incansável, os ovos do Schistosoma mansoni ainda não foram encontrados, mas muitas outras coisas interessantes foram observadas e registradas, moldando uma nova área de estudo, a paleoparasitologia. É um campo de estudo que requer a interdisciplinaridade, conjugando conhecimentos de arqueologia, antropologia, geologia, evolução, genética etc. Requer ainda exercer com certo risco o transporte de cadáveres ou de seus coprólitos, o que muitas vezes impõe sonegar informações às autoridades alfandegárias e até mesmo fazer contrabando. Em seu livro, Luiz Fernando narra algumas histórias engraçadas, cheias de suspense, sobre o transporte de fezes, corpos despedaçados ou ossos de múmias feito por ele e por outros pesquisadores. A busca de tais materiais também os leva em viagem pelo mundo, verdadeiras aventuras no mais legítimo estilo Indiana Jones.

Seus estudos têm permitido traçar generalizações sobre o comportamento de populações arcaicas e contribuído para a melhor compreensão da história das doenças. A convivência dos parasitas com o organismo humano é tão antiga quanto a sua origem. Os achados de trabalhos de sua autoria e de seus colaboradores mostram a ancilostomose há 7.000 anos no Piaú e a origem filogenética do Tridhuristrichuria em relação ao homem. Diversos outros ovos e larvas de outros parasitas foram encontrados em material humano e de fósseis animais. Ainda há formas parasitárias não diagnosticadas na coleção recolhida pelo seu grupo de pesquisa, mantendo permanente o desafio para diversas outras descobertas e a motivação inicial de encontrar os ovos de Schistosoma monsoni e esclarecer, então, a origem da esquistossomose na América.

Um pouco desta história foi enriquecido pelo Adauto, que aceitou meu pedido e enviou um relato sobre o seu encontro com Luiz Fernando e com 
a paleoparasitologia, o qual exemplifica uma genuína e produtiva relação mestre-orientando, perpassada pelo bom relacionamento humano, que é fundamental.

\section{Velhos Tempos (Adauto Araújo)}

A partir do segundo ano de medicina, interessei-me por parasitologia. Fui monitor e depois interno no departamento chefiado pelo Professor Ottílio Machado. Formado, aguardando concurso na UFRJ, cheguei certo dia à faculdade e Ottílio me disse: "Vá até Manguinhos inscrever-se no curso de mestrado em parasitologia da Ensp". "Agora?" "Sim, fale com Luiz Fernando. Ele é o coordenador".

Lá fui eu, incerto sobre o que dizer ou fazer. Cheguei e me apresentei. Luiz Fernando estava no gabinete do diretor, com Gilberto de Freitas, idealizador do curso junto com ele. "Foi Ottílio quem mandou você?? Se foi meu irmãozinho, está aceito. Vá até a secretaria e faça a inscrição!" (Bem, não foi tão fácil: tive que fazer uma prova, passar por seis meses de um curso de adequação com os colegas da primeira seleção e por outra prova, na qual foram eliminados mais dez. Aí, sim, entrei para o mestrado de Manguinhos).

Naqueles tempos, deixava-se para escolher o assunto de tese mais para o fim do curso. Falei com Ottílio, definimos que a minha seria sobre tricomoníase, levantei a bibliografia e fui falar com Luiz Fernando. Ele discutia com alguns colegas sobre a presença da xistosomose mansônica na América pré-colombiana, e dizia que a única maneira de provar sua hipótese seria encontrar ovos do parasito em fezes fósseis. Ligou para o diretor do Instituto de Arqueologia Brasileira, professor Ondemar Dias, e explicou o problema, enquanto aguardávamos a reação à sua pergunta sobre cocô de múmias coletado de sítios arqueológicos. A resposta foi um alívio: "Caramba! Você está interessado nisso? Tenho quilos! Ninguém até hoje se interessou em estudá-los!" 
Mudei o assunto da tese por sugestão sua (sem nenhuma reclamação de seu irmãozinho Ottílio), e nasceu a paleoparasitologia, de uma idéia iluminada de um pesquisador que sempre soube usar a imaginação, a competência, a cultura e o estímulo aos mais novos. Naquela altura ele já era diretor da Ensp; enquanto eu ficava no laboratório olhando lâminas, ele estava no gabinete. Mas havia uma condição: a todo novo achado eu tinha obrigação de chamálo imediatamente. E assim era: não importava o que estivesse fazendo, mesmo que fossem reuniões importantes do Conselho Deliberativo, ficava suspenso enquanto ele subia ao sexto andar para confirmar no microscópio um novo diagnóstico de ovos de ancilostomídeos. O entusiasmo que demonstrava com os primeiros resultados é o mesmo até hoje. A cada nova descoberta - novas técnicas incorporadas, novos pesquisadores de outras áreas interessados na sua paleoparasitologia e, principalmente, pesquisadores "de fora falando de nós!" -, uma comemoração.

PS. Até hoje ele não encontrou ovos de Schistosoma mansoni em coprólitos, mas continua a procurar.

\section{Memórias da Escola Nacional de Saúde Públịca}

No decorrer da conversa, Luiz Fernando contou alguns episódios do início de sua carreira na Ensp, um testemunho histórico de um tempo bem diferente. Como relata, foi em 1966 que se instalou pela primeira vez na Ensp um quadro geral de professores. Tudo começou com o Edmar Terra Blois e o Sávio Antunes, então diretores, que contrataram os primeiros professores permanentes. Naquela época, Luiz Fernando trabalhava como professor de parasitologia na cadeira de medicina tropical da UFRJ, junto com a Dra. Léa Coura, na equipe do Prof. José Rodrigues da Silva. Desenvolvia estudos de parasitologia e dava cursos. E o Blois o convidou para vir para a Ensp.

Como relata Luiz Fernando, naquele tempo a Ensp era uma loucura. Não era ainda unidade da Fiocruz. Era uma fundação de ensino de especialização 
em saúde pública. OIOC era separado. Rocha Lagoa quis fazer uma fundação para o IOC. Havia muitas exigências legais, e não deu para fazer. Então ele deu um golpe: pôs o IOC dentro da fundação que já existia e mudou o nome para Fundação Oswaldo Cruz. A Ensp foi então incorporada. Naquele tempo, Blois era amigo do Leonel Miranda, ministro da Saúde. Portanto, tinha poder, o que se refletia na Ensp. Isto aqui era um fausto, um luxo, cada chefe tinha o seu automóvel. O restaurante era servido por garçons com gravatas, em mesas postas com a etiqueta correta. O quinto e o sexto andares serviam de alojamento, um de moças e o outro de rapazes. Vinham estudantes de todo o Brasil. Eram quartos para duas pessoas, bem decorados, um ambiente luxuoso.

Luiz Fernando decidiu-se pela Ensp, apresentando então ao Blois o seu currículo. Era ainda jovem e concorria com profissionais mais antigos. Segundo conta, o Blois exigia um contrato por tempo integral, de dedicaçã̃o exclusiva: "Os parasitologistas mais antigos já tinham compromissos, e assim o lugar ficou para mim". O Blois me perguntou: "Quanto você quer ganhar? Quanto ganha na UFRJ? Três vezes mais está bom?” Ele era um homem corajoso e realizou uma série de inovações na Ensp. Uma delas foi a criação do Departamento de Ciências Sociais. Em 1966, isso foi pioneiro. Colocou um grupo de jovens e propiciou-lhes boas condições de trabalho. Achava que o pessoal das ciências sociais precisava conhecer o Brasil. Então, contratou um ônibus que foi pelo Rio São Francisco e terminou a viagem no Recife, onde houve um seminário, na Fundação Joaquim Nabuco, sobre o Brasil. Era um clima de liberdade, você podia criar, ousar, ter novas idéias.

Ele tinha lá algumas excentricidades e, assim, acabou sendo afastado do cargo. Gostava de mostrar que tinha muitas mulheres. A história de Blois termina em 1968, no dia de abertura dos cursos da Ensp. Era uma cerimônia pomposa, com a presença de secretários de Saúde, autoridades diversas e pessoas importantes do Ministério da Saúde. Todos de terno, mulheres arrumadíssimas. A cerimônia preparada, o auditório lotado, e o Blois não chegava. O atraso foi causando impaciência e muitos, já cansados de esperar, foram para fora. De repente, Blois chega, pára um Karmanguia 
vermelho - carro da moda naquele tempo - na porta, camisa aberta, sapato sem meia. Pula por cima da porta, pega pelo braço uma garota de minissaia e decote generoso, leva-a até a mesa do auditório, senta-se ao lado dela e abre a cerimônia. Este foi o seu último ato. Caiu sumariamente logo depois. Excentricidades à parte, ele tinha uma criação intelectual fabulosa e dava apoio a todos que queriam produzir.

Apoiado pelo Blois, Luiz Fernando pôde criar e tornar-se chefe do Departamento de Ciências Biológicas, como professor titular de parasitologia. Trabalhou com Herman Schatzmayer, Akira Homma e Sérgio Coutinho. $O$ Dr. Herman era professor titular de microbiologia no departamento chefiado pelo Luiz Fernando. Para ilustrar o estilo de direção praticado pelo Blois, Luis Fernando conta um episódio interessante: Dr. Herman queria trazer um importante especialista da OMS. O sujeito veio e o seu desempenho não correspondeu às expectativas. Herman chegou à conclusão de que ele estava, na verdade, atrapalhando em vez de ajudar. Ao levar o caso ao Blois, este foi direto: "Você quer que eu ponha o sujeito daqui para fora?" Afinal, o cara queria pôr todo mundo para trabalhar para ele, em lugar de colaborar, para o que havia sido de fato convidado. Invertia a situação acintosamente. Pois o Blois ordenou: "Manda esse cara vir até aqui". E foi franco: "Seu moleque, ponha-se daqui para fora", resolvendo a situação sem rodeios e receios. Ele era assim, franco e despachado, sem nove horas.

Com a saída intempestiva do Blois, veio o Sebastião, sucessor indicado pelo próprio Blois e, logo a seguir, o enquadramento como fundação. A gente sabe muito bem que o IOC, depois de Oswaldo Cruz e do Carlos Chagas, tornou-se burocratizado. Com o Blois, não tinha burocracia, ele resolvia tudo pessoalmente e na hora. O Santoro, que era o administrador na época do Blois, resolvia tudo. A gente chegava e dizia: "Preciso de úma estufa". Blois chamava: "Santoro, providencia logo a estufa para o Dr. Luiz Fernando, quero isso aqui amanhâ".

Outra contribuição do Blois foi na estruturação do curso de saúde pública. $\mathrm{O}$ antigo começou no IOC e depois foi transferido para a Ensp. 
Era dado em separado para médicos, enfermeiros, veterinários, engenheiros sanitários, ou seja, um para cada tipo de profissional. O Blois integrou tudo, tornando-se então um curso só, que foi o embrião do curso de especialização e, posteriormente, do mestrado e doutorado em saúde pública - agora já com subdivisões por áreas específicas.

Pergunto pela Ensp hoje. Luiz Fernando destaca os trabalhos na área de epidemiologia, os modelos matemáticos com o Cláudio Struchiner, o Paulo Sabroza nas endemias, os estudos de epidemiologia da hipertensão e a qualidade dos cursos de mestrado e doutorado, cada vez melhores.

Embora tenha apresentado aqui o Luiz Fernando cientista e professor, é preciso evidenciar as suas múltiplas faces, capaz como é de conciliar o cientista, o professor, o cronista, o poeta, o contador de histórias, o eterno enamorado. O que diz, com modéstia, ser herança, pois seu pai era médico e fazia poesia e peças de teatro. Movendo-se entre a paleoparasitologia e a poesia, deixo falar agora Ludovicus Tertius Guanabarimus, seu pseudônimo no livro Poetas deManouinhos, ${ }^{67}$ no qual estabelece uma ponte entre o castelo da ciência e o castelo de poesias, onde

Cadamosaico

Cadacorrimão

Cada vitral

Cadatijolo

Hojeéum poema em construção.

67 TEIXEIRA, P. \& FERREIRA, L. F. Poetas de Manguinhos. Rio de Janeiro: CCM (Cooperativa Cultural de Manguinhos) e Asfoc/Fiocruz, 1997.

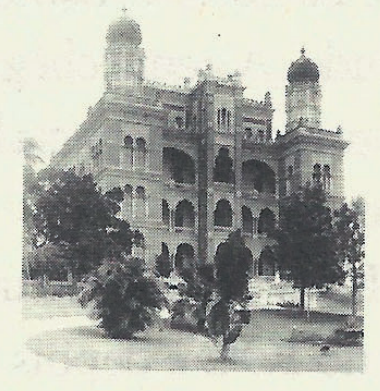




\section{Luiz Fernando Ferreira ${ }^{68}$}

Faço questão de assegurar com toda a clareza que absolutamente não tenho a intenção de colocar a minha pessoa num lugar de destaque, ao escrever algumas palavras acerca de mim mesmo e de minhas atividades...

Thomas Mann, Doutor Fausto ${ }^{69}$

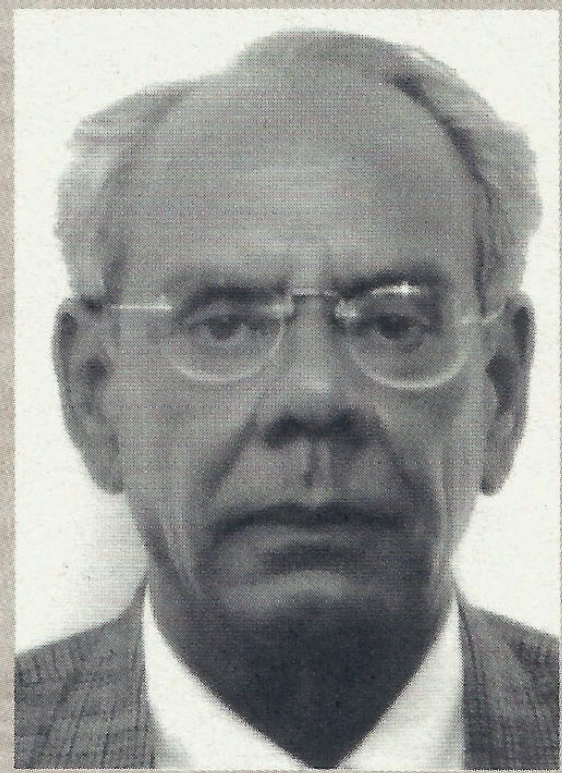

Dr. Luiz Fernando nasceu na cidade do Rio de Janeiro a 23 de setembro de 1936. De sua infância passada em um ambiente familiar, ele próprio destaca a biblioteca, onde os clássicos da literatura universal e os livros de filosofia, biologia e medicina cedo despertaram o seu gosto pela leitura e pelo trabalho intelectual. Como relata, ainda adolescente chegou-lhe às mãos o livro Caçadores de Micróbios, de Paul de Kruif, o qual, com as histórias de Oswaldo Cruz e de Manguinhos contadas pelo Dr. Marques, parente de seu tio Eduardo Marques Tinoco, definiram a sua opção profissional ainda antes de entrar para a faculdade. Formou-se em medicina na então Faculdade Nacional de Medicina da Universidade do Brasil, tendo estagiado no Instituto de Biofísica, nas cadeiras de bioquímica, de parasitologia e de clínica médica. Publicou o seu primeiro trabalho científico, relacionado à esquis-

\footnotetext{
${ }^{68}$ Extraída de uma autobiografia cedida pelo autor.

${ }^{69}$ Frase incluída pelo Dr. Luiz Fernando em sua biografia.
} 
tossomose, em 1958. Naquele mesmo ano foi aprovado em concurso para monitor oficial da cadeira de clínica das doenças infecciosas e parasitárias, chefiada pelo Prof. José Rodrigues da Silva. A partir de 1960, a convite do mesmo professor, continuou como bolsista do conselho de Pesquisa da Universidade, instrutor de ensino e assistente. Em 1966, a convite de Edmar Terra Blois, passou a professor titular de parasitologia da Ensp, onde fundou o Departamento de Ciências Biológicas, do qual tornou-se chefe. com a incorporação da Ensp à Fiocruz, criou, junto com outros pesquisadores do instituto, a pós-graduação stricto sensu em Manguinhos, fundando o curso de mestrado em parasitologia e virologia, hoje reunidos no Programa de Pós-Graduação em Biologia Parasitária. Na Fiocruz, foi também vicediretor e diretor da Ensp, assim como vicepresidente e presidente interino da instituição. Em sua gestão como vice-presidente, participou, com Sérgio Arouca e Arlindo Fábio comes de Sousa, da criação de duas novas unidades na Fiocruz: a Escola Politécnica Joaquim Venâncio e a casa de Oswaldo cruz. Foi também o idealizador e coordenador do Núcleo de Estudos da Saúde de Populações Indígenas. Foi professor titular de parasitologia da Escola de Ciências Médicas de Volta Redonda e da Escola Médica da Universidade Gama Filho. Tem orientado inúmeros alunos de mestrado e doutorado. Em 1978, passou a desenvolver estudos de paleoparasitologia, sobre a qual criou uma área de concentração na pós-graduação em saúde 
pública e publicou dois livros. ${ }^{70} \mathrm{Em} 1993$, foi eleito membro titular da Academia Brasileira de Medicina Militar. Publicou cerca de 102 artigos científicos e apresentou 71 trabalnos em congressos. Sua produção literária inclui livros de crônicas e de poesia. como editor e autor, organizou recentemente as coletâneas Poetas de Manguinhos (1997) e Prosas de Manguinhos (1998).

${ }^{70}$ FERREIRA, L. F; ARAÚJO, A. \& CONFALONIERI, U. Paleoparasitologia no Brasil. Rio de Janeiro: PEC/Ensp, 1988.

FERREIRA, L F. \& ARAÚJO, A. Paleopatologia e Paleoepidemiologia. Rio de Janeiro: PEC/Ensp, 1992. 